\title{
Is There Any Difference in the Outcome of Geriatric and Non-Geriatric Severely Injured Patients?-A Seven-Year, Retrospective, Observational Cohort Study with Matched-Pair Analysis
}

\author{
Kai O. Jensen ${ }^{1, *}$, Maximilian Lempert ${ }^{1}$, Kai Sprengel ${ }^{1}{ }^{\mathbb{D}}$, Hans P. Simmen ${ }^{1}$, Carina Pothmann ${ }^{1}$, \\ Mathias Schlögl ${ }^{2}$, Heike A. Bischoff-Ferrari ${ }^{3}$, Christian Hierholzer ${ }^{1}$, Hans C. Pape ${ }^{1}$ and \\ Valentin Neuhaus ${ }^{1}$ (D) \\ 1 Department of Trauma, University Hospital Zurich, University of Zurich, 8091 Zurich, Switzerland; \\ maximilian.Lemper@@usz.ch (M.L.); kai.sprengel@usz.ch (K.S.); hanspeter.simmen@usz.ch (H.P.S.); \\ carina.pothmann@usz.ch (C.P.); christian.hierholzer@usz.ch (C.H.); hans-christoph.pape@usz.ch (H.C.P.); \\ valentin.neuhaus@usz.ch (V.N.) \\ 2 University Clinic for Acute Geriatric Care, City Hospital Waid, 8037 Zurich, Switzerland; \\ mathias.schloegl@waid.zuerich.ch \\ 3 Department of Geriatrics and Ageing Research, University Hospital Zurich, University of Zurich, \\ 8091 Zurich, Switzerland; heike.bischoff@usz.ch \\ * Correspondence: kaioliver.jensen@usz.ch; Tel.: +41-442551111; Fax: +41-442554466
}

Received: 17 September 2020; Accepted: 30 October 2020; Published: 3 November 2020

\begin{abstract}
Geriatric trauma is expected to increase due to the lifestyle and activity of the aging population and will be among the major future challenges in health care. Therefore, the aim of this study was to investigate differences between polytraumatized geriatric and non-geriatric patients regarding mortality, length-of-stay and complications with a matched pair analysis. We included patients older than 17 years with an Injury Severity Score (ISS) of 16 or more admitted to our level 1 trauma center between January 2008 and December 2015. The cohort was stratified into two groups (age $<70$ and $\geq 70$ years). One-to-one matching was performed based on gender, ISS, mechanism of injury (penetrating/blunt), Glasgow coma scale (GCS), base excess, and the presence of coagulopathy (international normalized ratio (INR) $\geq 1.4$ ). Outcome was compared using the paired $t$-test and McNemar-test. A total of 1457 patients were identified. There were 1022 male (70\%) and 435 female patients. Three hundred and sixty-four patients $(24 \%)$ were older than 70 years. Matching resulted in 57 pairs. Mortality as well as length-of-stay were comparable between geriatric and non-geriatric polytraumatized patients. Complication rate $(34 \%$ vs. $56 \%, p=0.031)$ was significantly higher in geriatric patients. This indicates the possibility of similar outcomes in geriatric polytraumatized patients receiving optimal care.
\end{abstract}

Keywords: outcome; geriatric trauma; polytrauma; matched pair analysis

\section{Introduction}

Demographic changes are ubiquitous and cause a growing number of elderly patients. In Switzerland, we expect an increase in people aged 65 years and above from $29.1 \%$ of the population in 2015 up to $48.1 \%$ in 2045 [1]. A similar increase can be expected for most of Europe [2]. Recent studies report that patients over 65 years already account for $23 \%$ of all trauma admissions and that trauma is the fifth leading cause of death in this group of the population [3,4]. 
Despite its growing importance in medicine, geriatric trauma has not been defined in a universally accepted way. Some clinicians use an age threshold as an accepted distinction. The definition of what might be geriatric age, however, ranges from 60 up to 75 years of age [5-8].

Furthermore, elderly people are living an increasingly independent and active lifestyle [9]. As a consequence, a growing number of elderly patients sustain severe injuries in unintentional incidents [10-13]. This poses a challenge in trauma care, since advanced age alone is regarded as a risk factor for adverse outcomes in trauma $[9,14]$. Champion et al. reported in 1990 a three times higher mortality after trauma in older patients ( $>70$ years) compared to persons less than 55 years of age [15]. Mortality was found to be six-fold higher compared to younger patients with the same degree of injury [16]. Elderly patients have reduced physiological resources making them more prone to complications regardless of the injury or comorbidities, thus limiting their potential to respond to trauma, shock, and hypoxia [17-19]. Recent studies have shown that in the elderly patient with severe injuries, age and Injury Severity Score (ISS) are independently linked to mortality [20-22]. Furthermore, concomitant diseases also contribute to mortality in the elderly, but the effects seem to fade away with an increasing ISS [23,24].

Due to the current lack in the literature, the aim of our study was to determine whether there are differences between geriatric and non-geriatric patients in (1) mortality, (2) length of stay, and (3) complications due to age in a matched-pair analysis of severely injured patients.

\section{Methods}

In this retrospective database study, we analyzed all polytraumatized patients (orthopedic and non-orthopedic) admitted to a Level-1-trauma center between January 2008 and December 2015.

\subsection{Patients}

The inclusion criteria were all adult trauma patients (older than 17 years) with an ISS, coded by a trained study nurse, of 16 or more to evaluate severely injured patients [25], who were primarily or secondarily admitted to our Level-I trauma center. Exclusion criteria were missing data. Data were prospectively collected —in accordance with the German Trauma Registry DGU ${ }^{\circledR}$ —in four consecutive time phases from the site of the injurious incident until discharge from hospital: (A) pre-hospital phase, (B) emergency room and initial surgery, (C) intensive care unit, and (D) discharge. The documentation includes detailed information about demographics, injury pattern, comorbidities, pre- and in-hospital management, clinical course on intensive care unit, relevant laboratory findings including data on transfusion, and outcome of each individual. More specifically, the following parameters were collected: patient demographics (age, gender, trauma mechanism), Glasgow coma scale (GCS) [26] at admission, abbreviated injury score (AIS) [27] for each region, ISS [27], American Society of Anesthesiologists-Score (ASA-score) [28], hemodynamic parameters (systolic blood pressure (SBP) and pulse rate (PR) at admission), laboratory values (serum hemoglobin levels, serum hematocrit, lactate levels, base excess levels, thrombocyte counts, international normalized ratio (INR)) at admission, and comorbidities. Professional medical coders coded the injuries, diseases, and the procedures. Complications were defined in the presence of the corresponding International Classification of Diseases (ICD-10) code of an acute disease, such as acute hemorrhagic anemia (hemoglobin $<117 \mathrm{~g} / \mathrm{L}$ ), sepsis (Systemic inflammatory response syndrome (SIRS) criteria [29] (SIRS = two or more of the following criteria being met: temperature $\geq 38.0^{\circ} \mathrm{C}$ or $\leq 36.0^{\circ} \mathrm{C}$, tachycardia with heart rate $\geq 90 / \mathrm{min}$, respiratory rate $\geq 20 / \mathrm{min}$ or $\mathrm{PaCO} 2 \leq 4.3 \mathrm{kPa}$ or $33 \mathrm{mmHg}$, leukocytes $>20,000 / \mathrm{mm}^{3}$ or $\leq 4000 / \mathrm{mm}^{3}$ ) and any positive microbiological sample), urinary tract infection (positive microbiological urin sample), respiratory failure (need for intubation) as well as pneumonia (positive microbiological sample and radiological findings), acute renal failure (RIFLE criteria [30]), pulmonary embolus (radiological (ct) findings), deep vein thrombosis (detection in ultrasound), myocardial infarction (Electro cardiographie(ECG) changes or laboratory findings), surgical site infection (laboratory and clinical findings), wound dehiscence, and delirium. 


\subsection{Outcome}

Primary outcome parameters were (1) in-hospital mortality, (2) length of hospital stay (LOS), and (3) occurrence of the complications mentioned above.

\subsection{Case-Matched Design}

We identified 1464 consecutive polytraumatized patients. In order to establish a matched-pair analysis the cohort was stratified into two age groups. One group consisted of patients aged less than 70 years ("non-geriatric", $n=1117$ ), the other group of patients equal or older to 70 years ("geriatric", $n=346$ ). The age border 70 years was chosen due to in-hospital protocols and the associated geriatric co-management. Next, one-to-one pairing was performed by the statistical software program based on gender, exact ISS, mechanism of injury (penetrating/blunt), exact GCS at admission, base excess (tolerated variance \pm 1 ), and the presence of coagulopathy (dichotomized; defined as an INR $\geq 1.4$ ). These are the most frequently used covariates in trauma mortality studies [31]. This matching will allow the comparison of the effect of age on outcome after following trauma.

\subsection{Statistical Analysis}

Additional statistical analysis was performed using SPSS ${ }^{\circledR}$ for Windows 24.0 (SPSS, Chicago, IL, USA). Outcome as well as baseline values were compared between groups. The matched-pair analysis was performed using a paired $t$-test and McNemar-test. Data were presented as the mean \pm standard deviation for continuous and as absolute and relative numbers for categorical factors. $p$-values less than 0.05 were considered significant.

\subsection{Ethics Approval and Consent to Participate}

The institutional review board (IRB) and cantonal ethical review board approved the study (KEK-ZH-No. 2011-0382, PB_2016_01888), and this study was performed in accordance with the ethical standards laid down in the 1964 Declaration of Helsinki and its later amendments.

\section{Results}

For this study, 1457 patients with a mean age of $62( \pm 21)$ years were identified (Table 1). A total of 1022 male (72\%) and 435 female patients were included with 346 patients aged 70 years or older. The mean ISS in the entire cohort was calculated as 32 points $( \pm 17)$, following $95.1 \%$ blunt trauma mechanism with a GCS of $9.5( \pm 5.8)$ points at admission. The most frequently diagnosed injuries in geriatric $(\mathrm{G})$, respectively, in non-geriatric (NG) trauma patients were traumatic brain injuries (G 89.5\%; NG 78.9\%), thoracic (G 62.3\%; NG 60.8\%),extremity injuries (G 49.0\%; NG 50.0\%), as well as abdominal injuries (G 19.3\%; NG 23.2\%). The initial base excess after matching was $-2.6( \pm 2.6)$. Coagulopathy after matching was present in $8.9 \%$.

Matching resulted in 57 pairs (Table 2). The mean age of the non-geriatric trauma patients was $47( \pm 16)$ years in contrast to $79( \pm 6.3)$ years $(p<0.001)$ in the geriatric trauma cohort.

Mortality $(25 \%$ vs. $32 \%$ respectively; $p=0.219)$ as well as length of stay $(12.5( \pm 13.3)$ days vs. $11.8( \pm 11.8)$ days respectively, $p=0.754)$ demonstrated no significant difference between geriatric and non-geriatric patients (Figures 1 and 2).

Patients were predominately discharged to rehabilitation (G 29.8\%; NG 36.8\%), back home (G 26.3\%; NG 19.3\%), or to another hospital (G 26.3\%; NG 19.3\%). Only the complication rate was significantly increased for geriatric patients (34\% vs. 56\%, $p=0.031$ ) (Figure 3). The most common complications in our cohort are shown in Figure 4. 
Table 1. Baseline characteristics and comparison between the age groups.

\begin{tabular}{|c|c|c|c|c|c|c|c|c|c|}
\hline & \multicolumn{4}{|c|}{ Age $<70$} & \multicolumn{4}{|c|}{ Age $\geq 70$} \\
\hline & & $n$ & $\%$ & Mean & $\begin{array}{l}\text { Standard } \\
\text { Deviation }\end{array}$ & $n$ & $\%$ & Mean & $\begin{array}{l}\text { Standard } \\
\text { Deviation }\end{array}$ \\
\hline \multirow{2}{*}{ gender } & female & 276 & $24.8 \%$ & & & 159 & $46.0 \%$ & & \\
\hline & male & 835 & $75.2 \%$ & & & 187 & $54.0 \%$ & & \\
\hline \multirow{2}{*}{$\begin{array}{c}\text { trauma } \\
\text { mechanism }\end{array}$} & penetrating & 68 & $6.1 \%$ & & & 3 & $0.9 \%$ & & \\
\hline & blunt & 1043 & $93.9 \%$ & & & 343 & $99.1 \%$ & & \\
\hline \multicolumn{2}{|c|}{ ISS (points) } & & & 31 & 15 & & & 37 & 22 \\
\hline \multicolumn{10}{|l|}{ At admission } \\
\hline \multicolumn{2}{|c|}{ heart rate (beats/min) } & & & 91 & 23 & & & 85 & 21 \\
\hline \multicolumn{2}{|c|}{ systolic blood pressure (mmHg) } & & & 125 & 26 & & & 133 & 29 \\
\hline \multicolumn{2}{|c|}{ base excess (mmol/L) } & & & -4.1 & 4.8 & & & -3.6 & 4.4 \\
\hline \multicolumn{2}{|c|}{ lactate $(\mathrm{mmol} / \mathrm{L})$} & & & 2.5 & 2.3 & & & 2.2 & 2.1 \\
\hline \multicolumn{2}{|c|}{ haemoglobin (g/L) } & & & 11.43 & 2.60 & & & 10.93 & 2.22 \\
\hline \multicolumn{2}{|c|}{ haematokrit (L/L) } & & & 33.26 & 7.30 & & & 32.15 & 6.12 \\
\hline \multicolumn{2}{|c|}{ thrombocytes $\left(10^{3} / \mu \mathrm{L}\right)$} & & & 204 & 72 & & & 186 & 77 \\
\hline \multicolumn{2}{|c|}{ GCS (points) } & & & 10 & 5 & & & 9 & 5 \\
\hline \multicolumn{2}{|c|}{ presence of coagulopathy (INR > 1.4) } & 237 & $21.3 \%$ & & & 61 & $30.2 \%$ & & \\
\hline \multicolumn{10}{|l|}{ Outcome } \\
\hline \multicolumn{2}{|c|}{ death during hospitalisation } & 179 & $16.1 \%$ & & & 104 & $46.0 \%$ & & \\
\hline \multicolumn{2}{|c|}{ Length of stay (days) } & & & 17 & 19 & & & 10 & 11 \\
\hline \multicolumn{2}{|c|}{ complications } & 593 & $53.4 \%$ & & & 158 & $45.7 \%$ & & \\
\hline
\end{tabular}

ISS: Injury Severity Score; GCS: Glasgow coma scale; INR: international normalized ratio.

Table 2. Matching results and base characteristics of the matched couples.

\begin{tabular}{ccccccc}
\hline Group & Male (\%) & Age (Years \pm SD) & ISS (Points \pm SD) & GCS (Points \pm SD) & BE (mmol/L \pm SD) & INR $\geq 1.4$ (\%) \\
\hline$n<70$ yo $(n=57)$ & 72 & $45 \pm 16$ & $33 \pm 22$ & $10 \pm 6$ & $-2.6 \pm 2.5$ & 8.9 \\
$n \geq 70$ yo $(n=57)$ & 72 & $79 \pm 6$ & $33 \pm 22$ & $10 \pm 6$ & $-2.6 \pm 2.7$ & 8.9 \\
\hline
\end{tabular}

SD: standard deviation; ISS: Injury Severity Score; GCS: Glasgow coma scale; BE: base excess; INR: International standardized ratio; yo: years old.

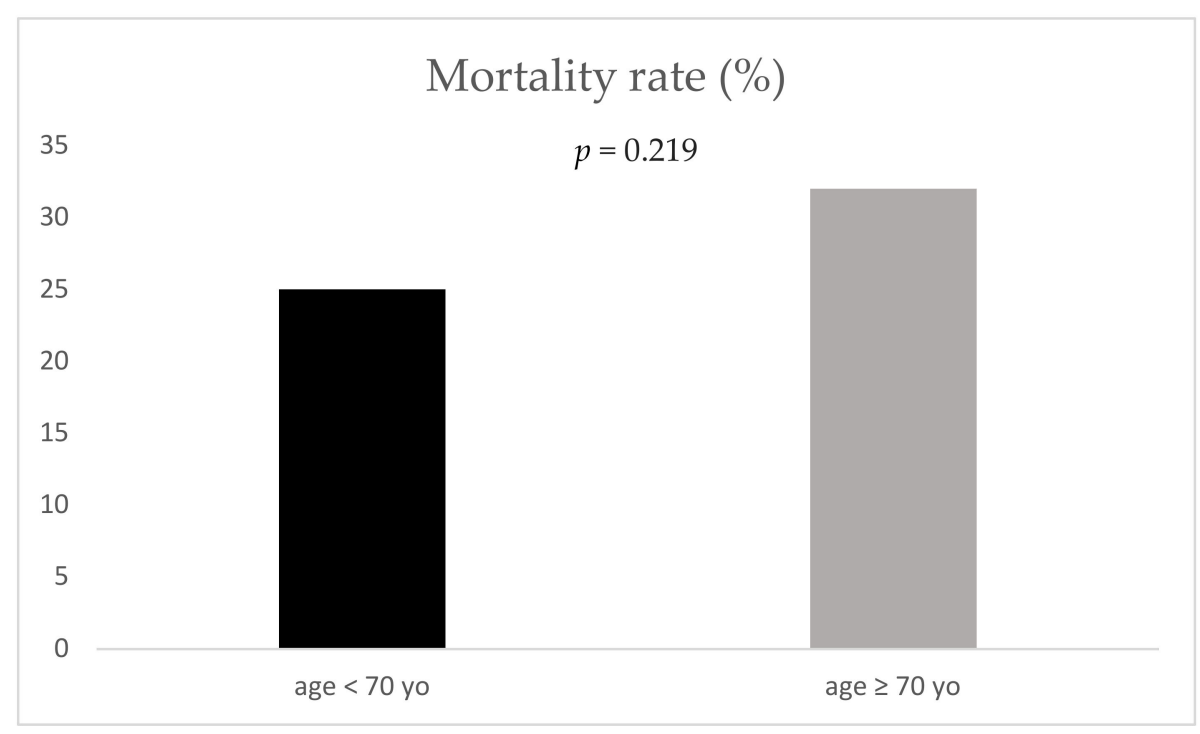

Figure 1. Mortality rate for the two age groups; yo: years old. 


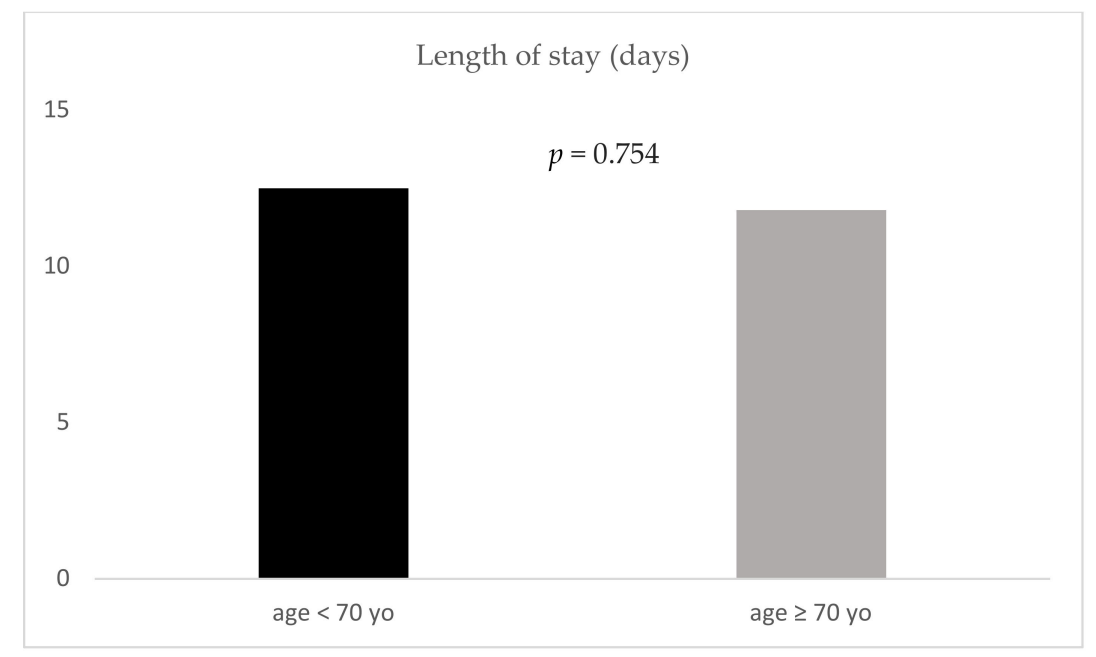

Figure 2. Length of stay for the two age groups; yo: years old.

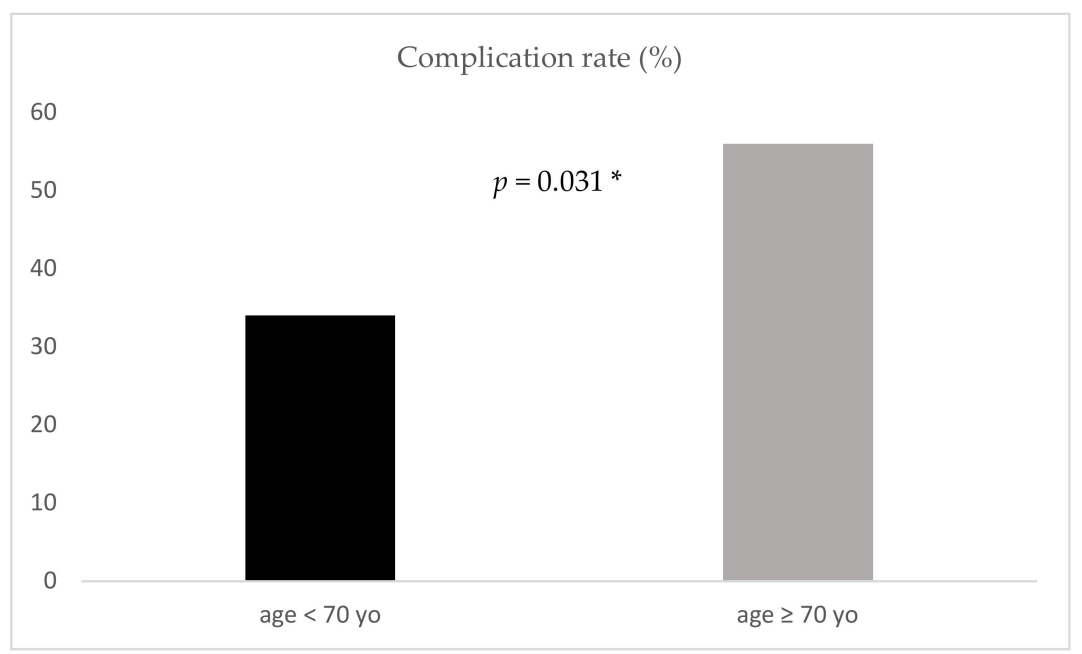

Figure 3. Complication rate for the two age groups; yo: years old; *: significant.

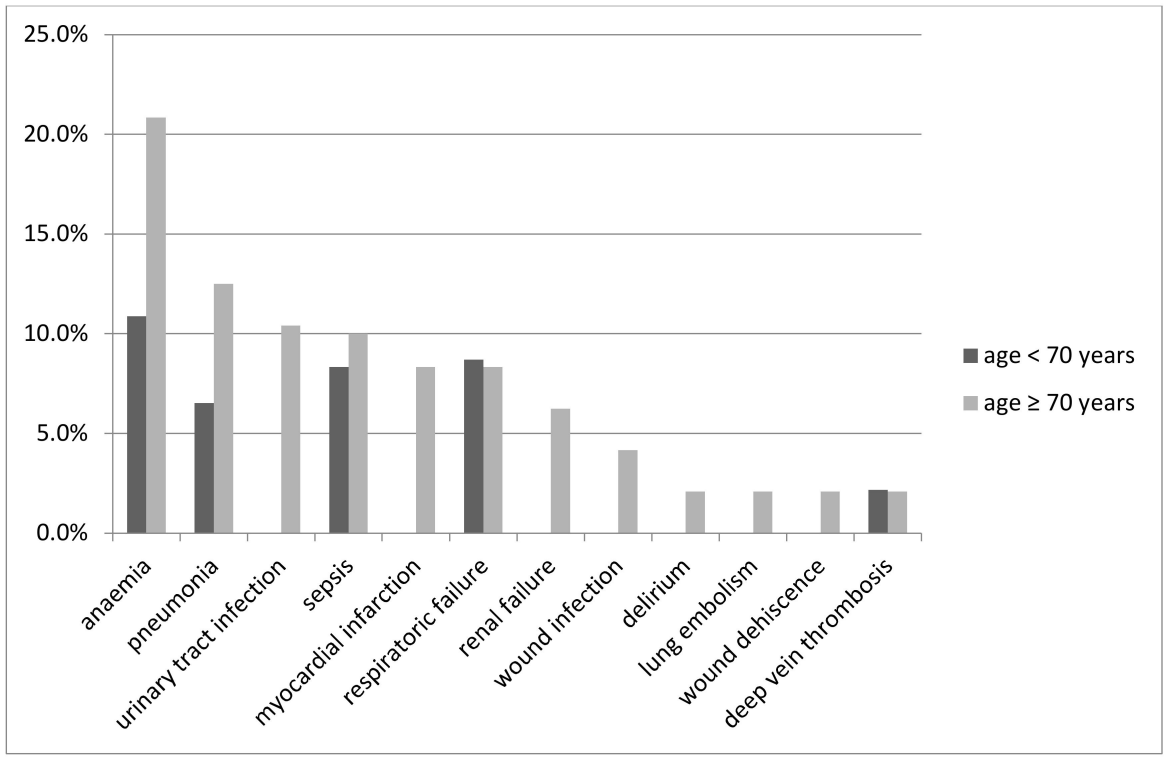

Figure 4. Type of complication for the two age groups. 


\section{Discussion}

The aim of our study was to investigate the differences in the outcome of elderly polytraumatized patients compared to young patients with the same gender, ISS, mechanism of injury, GCS at admission, base excess, and presence of coagulopathy.

Our main results after matching are as follows:

1. Mortality demonstrated no significant difference between geriatric and non-geriatric patients.

2. Length of stay demonstrated no significant difference between geriatric and non-geriatric patients.

3. Geriatric trauma patients had a significantly higher rate of complications.

\subsection{Strengths/Limitations}

The main strength of this study is the strict matching criteria which are all proven and validated predictors of outcome in trauma [20,32-35]. With this study concept, we were able to study the effect of age on the outcome of severely injured patients.

The strongest limitation of this study lies within its nature as a retrospective register study. The available data are limited, and missing data cannot be accessed. Data concerning comorbidities, cognitive and motoric status/disabilities, or pre-existing medications are scarce and might change the results. The follow up is limited to the in-hospital results. Therefore, we cannot make any statements regarding long term mortality or morbidity. Furthermore, we could not match the pairs concerning comorbidities as they differed too much, or information was not sufficient.

\subsection{Mortality}

There was a trend towards increased mortality in the older group compared to the younger group, but the difference was not statistically significant. These results are in contrast to recent studies $[11,13,23]$. However, these studies did not use matched-pair analysis.

With the significantly increased rate of complications and additional predisposing negative factors for survival, one would expect a significantly higher mortality rate in the geriatric group. Possible reasons for this discrepancy may firstly be a higher rate of very early death in the older population, meaning that the most severely injured and vulnerable old patients died prior to hospital allocation or died in the resuscitation area in the emergency department, which led to a lack of data and, therefore, are not included in our data set. On the other hand, the rate of death in the consecutive medical course following hospital treatment is also higher in the elderly than in younger groups, possibly pointing to a larger portion of deaths of geriatric patients a short-time after discharge, which are also not recorded in our study $[13,36,37]$.

Furthermore, some of the matching criteria require critical discussion. Even though GCS, coagulopathy, Base Excess(BE), and ISS are considered to be strong predictors for adverse outcome in trauma [31], elderly patients present with more comorbidities, hence there might be a bias within the matching itself due to pre-existing conditions [20,32-35]. It is more likely that a pre-existing decreased GCS would be found in an older patient. The same may apply for the base excess. In contrast to a young patient, a pathological base excess in an old patient can be the consequence of a chronic disease. Even the coagulopathy may result from pre-existing medication. All these factors may lead to the matching of pairs with different severities of trauma resulting in the same ISS with consecutive differences in mortality. However, the results of the mortality rate amongst the older patients may also be considered very encouraging as it demonstrates the potential for recovery after severe injuries even in the older population.

The older patients overall stayed for a shorter time at the trauma unit than the patients in the younger group. This might be surprising, as they developed more post-traumatic complications than their younger counterparts. However, with older people more often living in (medical) facilities, some of them can be discharged earlier and in less favourable physical states because they receive 
medical care at home. Likewise, early hospital-intern transfer to an acute geriatric rehabilitation clinic after the acute phase from the trauma unit counts as discharge in the database.

\subsection{Complications}

We found a significantly higher rate of complications in the group of older patients compared to the younger ones after matching. This is consistent with the results of other groups $[13,18,36,38]$. Providing trauma care to geriatric patients is particularly challenging as these patients present with more comorbidities and smaller physiological reserves rendering them more susceptible to developing complications $[36,39,40]$, a clinical state that is defined as frailty [9,41]. A frail individual is more vulnerable to developing negative health related events when exposed to a stressor $[17,19,41,42]$. Frailty is not only found in the elderly, but its rate increases exponentially with age [43].

Typical complications were found in the group of elderly patients. First, the higher rates of anaemia might be multifactorial and partly be caused by the fact that anaemia in general is a more common pre-existing state in the elderly population rising up to $40 \%$ due to underlying diseases [44]. Second, we found elderly patients to have a significantly higher risk of developing an acute coronary syndrome, which matches the results of other groups even without the presence of trauma [45]. The additional factors of anaemia, due to blood loss, and the physiological stress of trauma might even further increase that risk. Unless the diagnosis of a myocardial infarction is made either by ECG changes or laboratory findings during the clinical course, there might be a slight overestimation of this complication when the patient suffers from a heart attack directly before the admittance. Third, another complication mainly amongst the older polytrauma patients was pneumonia. Due to physiological changes, comorbidities, and longer periods of immobilization in the elderly, they are generally more prone to pneumonia than their younger counterparts [40,46-48].

Another explanation for the higher rate of complications in older patients can also be found in the possible lack of diagnosis at the time of admission [40]. Older people are commonly admitted with a multitude of comorbidities requiring different types of medical treatment. Yet, after a major trauma, medical history might not be available at the point of admission, leading to pre-existing chronic diseases not being properly treated or to pharmaceutical interactions between the patient's standard and administered emergency-medications further aggravating the patient's physiological situation.

A very surprising result of our study was the low rate of delirium in elderly patients. Whereas de Vries et al. reported a delirium rate of $20.1 \%$ amongst elderly trauma patients [11], we only observed delirium in $2.1 \%$ of old patients. This finding bias might partly be explained by the incomplete application of screening tools to detect delirium in our cohort. At that time, a standardized screening method was lacking for diagnosing a delirium. Currently, all geriatric patients are screened for delirium and co-treated by geriatrics in our geriatric trauma centre.

\section{Conclusions}

With this matched pair analysis, we were able to demonstrate that geriatric patients and non-geriatric patients have similar rates of mortalities and lengths of stay in hospital even though the rate of complication was significantly higher in the older group. This is in indication that with the appropriate geriatric trauma care older severely injured people still have very favourable outcomes even compared to younger patients. Therefore, we think there is clearly a need to implement more dedicated geriatric trauma teams/centres to meet the specific needs of the injured geriatric patient. Furthermore, each geriatric patient must be assessed and evaluated individually, as chronologic age might not necessarily correlate with biological age.

Author Contributions: Conceptualization, K.O.J. and V.N.; Data curation, V.N.; Formal analysis, K.O.J., M.L. and V.N.; Investigation, K.O.J., M.L. and V.N.; Methodology, K.O.J. and V.N.; Project administration, K.O.J. and V.N.; Software, V.N.; Supervision, V.N.; Validation, K.S., H.P.S., C.P., M.S., H.A.B.-F., C.H. and H.C.P.; Visualization, K.O.J. and M.L.; Writing—original draft, K.O.J.; Writing—review and editing, K.S., H.P.S., C.P., M.S., H.A.B.-F., C.H. and H.C.P. All authors have read and agreed to the published version of the manuscript. 
Funding: This research received no external funding.

Conflicts of Interest: The authors declare no conflict of interest.

\section{References}

1. Schneider-Schneiter BdBiEdP. Demografischer Wandel in der Schweiz: Handlungsfelder auf Bundesebene; Schneider-Schneiter BdBiEdP: Basel, Switzerland, 2016.

2. Carone, G.; Costello, D. Can Europe Afford to Grow Old? Financ. Dev. 2006, 43, 28-31, Swiss confederation, Bern, Switzerland.

3. Thompson, H.J.; McCormick, W.C.; Kagan, S.H. Traumatic Brain Injury in Older Adults: Epidemiology, Outcomes, and Future Implications. J. Am. Geriatr. Soc. 2006, 54, 1590-1595. [CrossRef] [PubMed]

4. Keller, J.M.; Sciadini, M.F.; Sinclair, E.; O’Toole, R.V. Geriatric trauma: Demographics, injuries, and mortality. J. Orthop. Trauma 2012, 26, e161-e165. [CrossRef]

5. Battistella, F.D.; Din, A.M.; Perez, L. Trauma Patients 75 Years and Older. J. Trauma Inj. Infect. Crit. Care 1998, 44, 618-624. [CrossRef]

6. Grossman, M.D.; Miller, D.; Scaff, D.W.; Arcona, S. When Is an Elder Old? Effect of Preexisting Conditions on Mortality in Geriatric Trauma. J. Trauma 2002, 52, 242-246. [CrossRef]

7. McMahon, D.J.; Schwab, C.W.; Kauder, D. Comorbidity and the Elderly Trauma Patient. World J. Surg. 1996, 20, 1113-1120. [CrossRef]

8. Shorr, R.M.; Rodriguez, A.; Indeck, M.C.; Crittenden, M.D.; Hartunian, S.; Cowley, R.A. Blunt Chest Trauma in the Elderly. J. Trauma 1989, 29, 234-237. [CrossRef] [PubMed]

9. Peterer, L.; Ossendorf, C.; Jensen, K.O.; Osterhoff, G.; Mica, L.; Seifert, B.; Werner, C.M.L.; Simmen, H.-P.; Pape, H.; Sprengel, K. Implementation of new standard operating procedures for geriatric trauma patients with multiple injuries: A single level I trauma centre study. BMC Geriatr. 2019, 19, 359. [CrossRef]

10. Bonne, S.; Schuerer, D.J. Trauma in the older adult: Epidemiology and evolving geriatric trauma principles. Clin. Geriatr. Med. 2013, 29, 137-150. [CrossRef] [PubMed]

11. De Vries, R.; Reininga, I.H.F.; De Graaf, M.W.; Heineman, E.; El Moumni, M.; Wendt, K.W. Older polytrauma: Mortality and complications. Injury 2019, 50, 1440-1447. [CrossRef] [PubMed]

12. Cox, G.; Jones, E.; McGonagle, D.; Giannoudis, P.V. Reamer-irrigator-aspirator indications and clinical results: A systematic review. Int. Orthop. 2011, 35, 951-956. [CrossRef]

13. Giannoudis, P.V.; Harwood, P.J.; Court-Brown, C.; Pape, H. Severe and multiple trauma in older patients; incidence and mortality. Injury 2009, 40, 362-367. [CrossRef]

14. Demetriades, D.; Sava, J.; Alo, K.; Newton, E.; Velmahos, G.C.; Murray, J.A.; Belzberg, H.; Asensio, J.A.; Berne, T.V. Old Age as a Criterion for Trauma Team Activation. J. Trauma Acute Care Surg. 2001, 51, 754-757. [CrossRef] [PubMed]

15. Champion, H.R.; Copes, W.S.; Sacco, W.J.; Lawnick, M.M.; Keast, S.L.; Bain, L.W., Jr.; E Flanagan, M.; Frey, C.F. The Major Trauma Outcome Study: Establishing national norms for trauma care. J. Trauma Acute Care Surg. 1990, 30, 1356-1365. [CrossRef]

16. Oreskovich, M.R.; Howard, J.D.; Copass, M.K.; Carrico, C.J. Geriatric trauma: Injury patterns and outcome. J. Trauma 1984, 24, 565-572. [CrossRef]

17. Adams, S.D.; Cotton, B.A.; McGuire, M.F.; Dipasupil, E.; Podbielski, J.M.; Zaharia, A.; Ware, D.N.; Gill, B.S.; Albarado, R.; Kozar, R.A.; et al. Unique pattern of complications in elderly trauma patients at a Level I trauma center. J. Trauma Acute Care Surg. 2012, 72, 112-118. [CrossRef]

18. Schiller, W.R.; Knox, R.; Chleborad, W. A five-year experience with severe injuries in elderly patients. Accid. Anal. Prev. 1995, 27, 167-174. [CrossRef]

19. Pudelek, B. Geriatric Trauma: Special Needs for a Special Population. AACN Adv. Crit. Care 2002, 13, 61-72. [CrossRef]

20. Pape, H.C.; Lefering, R.; Butcher, N.; Peitzman, A.B.; Leenen, L.; Marzi, I.; Lichte, P.; Josten, C.; Bouillon, B.; Schmucker, U.; et al. The definition of polytrauma revisited: An international consensus process and proposal of the new 'Berlin definition'. J. Trauma Acute Care Surg. 2014, 77, 780-786. [CrossRef]

21. Bala, M.; Willner, D.; Klauzni, D.; Bdolah-Abram, T.; I Rivkind, A.I.; Gazala, M.A.; Elazary, R.; Almogy, G. Pre-hospital and admission parameters predict in-hospital mortality among patients 60 years and older following severe trauma. Scand. J. Trauma Resusc. Emerg. Med. 2013, 21, 91. [CrossRef] 
22. Pfeifer, R.; Teuben, M.; Andruszkow, H.; Barkatali, B.M.; Pape, H.-C. Mortality Patterns in Patients with Multiple Trauma: A Systematic Review of Autopsy Studies. PLoS ONE 2016, 11, e0148844. [CrossRef]

23. Clement, N.D.; Tennant, C.; Muwanga, C. Polytrauma in the elderly: Predictors of the cause and time of death. Scand. J. Trauma Resusc. Emerg. Med. 2010, 18, 26. [CrossRef] [PubMed]

24. Hollis, S.; Lecky, F.; Yates, D.W.; Woodford, M. The effect of pre-existing medical conditions and age on mortality after injury. J. Trauma Acute Care Surg. 2006, 61, 1255-1260. [CrossRef]

25. Baker, S.P.; O’Neill, B.; Haddon, W., Jr.; Long, W.B. The injury severity score: A method for describing patients with multiple injuries and evaluating emergency care. J. Trauma Acute Care Surg. 1974, 14, 187-196. [CrossRef]

26. Teasdale, G.; Jennett, B. Assessment of coma and impaired consciousness. A practical scale. Lancet 1974, 304, 81-84. [CrossRef]

27. States, J.D. The Abbreviated and the Comprehensive Research Injury Scales. SAE Trans. 1969, 78, $2625-2634$. [CrossRef]

28. Saklad, M. Grading of Patients for Surgical Procedures. Anesthesiol. J. Am. Soc. Anesthesiol. 1941, 2, $281-284$. [CrossRef]

29. BBone, R.C.; Balk, R.A.; Cerra, F.B.; Dellinger, R.P.; Fein, A.M.; Knaus, W.A.; Schein, R.M.; Sibbald, W.J. Definitions for Sepsis and Organ Failure and Guidelines for the Use of Innovative Therapies in Sepsis. Chest 1992, 101, 1644-1655. [CrossRef]

30. Bellomo, R.; Ronco, C.; Kellum, J.A.; Mehta, R.L.; Palevsky, P. Acute Dialysis Quality Initiative workgroup. Acute renal failure-definition, outcome measures, animal models, fluid therapy and information technology needs: The Second International Consensus Conference of the Acute Dialysis Quality Initiative (ADQI) Group. Crit. Care 2004, 8, R204-R212. [PubMed]

31. Haider, A.H.; Saleem, T.; Leow, J.J.; Villegas, C.V.; Kisat, M.; Schneider, E.B.; Haut, E.R.; Stevens, K.A.; Cornwell, E.E.; MacKenzie, E.J.; et al. Influence of the National Trauma Data Bank on the study of trauma outcomes: Is it time to set research best practices to further enhance its impact? J. Am. Coll. Surg. 2012, 214, 756-768. [CrossRef]

32. Saad, S.; Mohamed, N.; Moghazy, A.; Ellabban, G.; El-Kamash, S. Venous glucose, serum lactate and base deficit as biochemical predictors of mortality in patients with polytrauma. Ulus Travma Acil Cerrahi Derg 2016, 22, 29-33.

33. Palmer, C.S.; Gabbe, B.J.; Cameron, P.A. Defining major trauma using the 2008 Abbreviated Injury Scale. Injury 2016, 47, 109-115. [CrossRef]

34. Gitajn, I.L.; Castillo, R.; Breazeale, S.; Schoonover, C.; Berger, P.; Huang, Y.; O'Hara, N.; O'Toole, R.V.; Sciadini, M.F. Survivorship After High-Energy Geriatric Trauma. J. Orthop. Trauma 2017, 31, e230-e235. [CrossRef]

35. Cohen, M.J.; Christie, S.A. Coagulopathy of Trauma. Crit. Care Clin. 2017, 33, 101-118. [CrossRef]

36. Erdue, P.W.; Watts, D.; Kaufmann, C.R.; Trask, A.L. Differences in mortality between elderly and younger adult trauma patients: Geriatric status increases risk of delayed death. J. Trauma Acute Care Surg. 1998, 45, 805-810.

37. Trunkey, D.D. Trauma. Accidental and intentional injuries account for more years of life lost in the U.S. than cancer and heart disease. Among the prescribed remedies are improved preventive efforts, speedier surgery and further research. Sci. Am. 1983, 249, 28-35. [CrossRef] [PubMed]

38. Pellicane, J.V.; Byrne, K.; DeMaria, E.J. Preventable complications and death from multiple organ failure among geriatric trauma victims. J. Trauma 1992, 33, 440-444. [CrossRef]

39. McMahon, D.J.; Shapiro, M.B.; Kauder, D.R. The injured elderly in the trauma intensive care unit. Surg. Clin. N. Am. 2000, 80, 1005-1019. [CrossRef]

40. Dimitriou, R.; Calori, G.M.; Giannoudis, P.V. Polytrauma in the elderly: Specific considerations and current concepts of management. Eur. J. Trauma Emerg. Surg. 2011, 37, 539-548. [CrossRef]

41. Morley, J.E.; Vellas, B.; van Kan, G.A.; Anker, S.D.; Bauer, J.M.; Bernabei, R.; Cesari, M.; Chumlea, W.; Doehner, W.; Evans, J.; et al. Frailty Consensus: A Call to Action. J. Am. Med. Dir. Assoc. 2013, 14, 392-397. [CrossRef]

42. Cesari, M.; Calvani, R.; Marzetti, E. Frailty in Older Persons. Clin. Geriatr. Med. 2017, 33, 293-303. [CrossRef]

43. Collard, R.M.; Boter, H.; Schoevers, R.A.; Oude Voshaar, R.C. Prevalence of Frailty in Community-Dwelling Older Persons: A Systematic Review. J. Am. Geriatr. Soc. 2012, 60, 1487-1492. [CrossRef] 
44. Gaskell, H.; Derry, S.; Moore, R.A.; McQuay, H.J. Prevalence of anaemia in older persons: Systematic review. BMC Geriatr. 2008, 8, 1. [CrossRef]

45. Veerasamy, M.; Edwards, R.; Ford, G.; Kirkwood, T.; Newton, J.; Jones, D.; Kunadian, V. Acute coronary syndrome among older patients: A review. Cardiol. Rev. 2015, 23, 26-32. [CrossRef]

46. Cabre, M. Pneumonia in the elderly. Curr. Opin. Pulm. Med. 2009, 15, 223-229. [CrossRef]

47. Tessler, R.A.; Rangel, M.M.; Rosser, M.L.; Rivara, F.P.; Bulger, E.; Vavilala, M.S.; Reed, M.J.; Arbabi, S. Complications in low-risk older adult trauma patients: A case-control study. J. Trauma Acute Care Surg. 2019, 86, 858-863. [CrossRef]

48. Janssens, J.-P.; Krause, K.-H. Pneumonia in the very old. Lancet Infect. Dis. 2004, 4, 112-124. [CrossRef]

Publisher's Note: MDPI stays neutral with regard to jurisdictional claims in published maps and institutional affiliations.

(C) 2020 by the authors. Licensee MDPI, Basel, Switzerland. This article is an open access article distributed under the terms and conditions of the Creative Commons Attribution (CC BY) license (http://creativecommons.org/licenses/by/4.0/). 